\title{
XИMИYECRИE HAYRИ
}

\section{ЗОЛЬ-ГЕЛЬ МЕТОД ФОРМИРОВАНИЯ МЕТАЛЛОКСИДНЫХ ГАЗОЧУВСТВИТЕЛЬНЫХ ПЛЕНОК НА ИНЕРТНОЙ ПОДЛОЖКЕ}

DOI: $10.31618 / E S U .2413-9335.2019 .4 .66 .316$

Абдурахманов И.Э.

Бегматов Р.

Абдурахманов Э.

Самаркандский госуниверситет,

$$
\text { 2. Самарканд. }
$$

\section{АННОТАЦИЯ}

В результате проведенных исследований влияния состава и соотношения компонентов пленкообразующих растворов на кинетику процесса гелеобразования исходного золя подобраны оптимальные параметры, обеспечивающие высокую устойчивость исходного раствора. Установлено, что наибольшей устойчивостью (от 18 до 18,5 суток) обладают растворы, полученные при соотношении исходных компонентов ТЭОС:Н2О:спирт: НС1=1:20:30:0,05.

\section{ANNOTATION}

As a result of studies of the influence of the composition and ratio of the components of the film-forming solutions on the kinetics of the gel formation process of the initial sol, optimal parameters are selected that provide high stability of the initial solution. It was established that the most stable (from 18 to 18,5 days) are the solutions obtained at a ratio of the initial components of TEOS: H2O: alcohol: $\mathrm{HC1}=1: 20: 30$ : 0.05.

Ключевые слова: золь-гель, тетраэтоксисилан, гидролиз, этанол, газочувстивительный пленок, сенсор, конденсация, нанокомпозит, оптимальная условия, полупроводник.

Keywords: sol-gel, tetraethoxysilane, hydrolysis, ethanol, gas-sensitive films, sensor, condensation, nanocomposite, optimal conditions, semiconductor.

Введение. В настоящее время полупроводниковые материалы находят все более широкое применение в качестве чувствительных элементов газовых сенсоров[1]. В зависимости от решаемой задачи, для получения полупроводниковых тонких пленок с воспроизводимыми и стабильными характеристиками используются различные методы. Из них получение газочувствительных пленок методом золь-гель технологии, является наиболее перспективным [2,3]. Этот метод в сочетании $\mathrm{c}$ последующей термообработкой продуктов реакции широко применяется для получения всевозможных оксидных нанокомпозиционных плёнок.

В работе нами изучено влияние соотношение компонентов исходного раствора на кинетику созревания плёнкообразующего золя.

Материалы и методы исследования.

В работе в качестве прикурсора алкоксисоединения, использован этиловый эфир ортокремневой кислоты - тетраэтоксисилан.

Определяющими параметрами перехода пленкообразующего раствора золя в гель является вязкость, электропроводность и устойчивость исходного раствора. Поэтому в опытах для контроля кинетику золь-гель процесса использованы вискозиметрические, кондуктометрические и газохроматографические методы анализа.

\section{Результаты и обсуждение}

В ходе экспериментов изучено влияние состава и соотношения компонентов исходного раствора на кинетику созревания золя. При этом мольные соотношения исходных компонентов варьировались в следующих интервалах: $\mathrm{Si}\left(\mathrm{OC}_{2} \mathrm{H}_{5}\right)_{4}: \mathrm{H}_{2} \mathrm{O}: \quad \mathrm{ROH}: \mathrm{HX}=(1-4):(1-40):(1-45)$ $:(0,01-0,3)$, где ROH - простые спирты, HX кислота.

Для выяснение механизма процесса пленкообразования и получения селективных газочувствительных пленок изучено влияние соотношения

ТЭОС:спирта в растворе от 1:1 до 1:45.

В результате проведенных исследований установлена возможность использования алифатических спиртов в качестве растворителя в процессе синтеза полупроводниковых газочувствительных пленок. В связи с учетом устойчивости раствора и растворимости компонентов гидролизата в качестве растворителя процесса синтеза газочувствительных пленок был выбран этанол. При этом оптимальное соотношение ТЭОС:этанол=1:30, обеспечивает наиболее высокую растворимость компонентов и устойчивость раствора.

Исследование влияния воды на устойчивость, электропроводность, плотность и вязкость золя в процессе синтеза газочувствительных пленок проводили на этанольном растворе при мольном соотношении ТЭОС: $\mathrm{H}_{2} \mathrm{O}$ от 1:1 до 1:40. Результаты экспериментов приведены в таблице 2. 
Таблица 2.

ВЛИЯНИЕ КОЛИЧЕСТВА ВОДЫ В РАСТВОРЕ НА ЕГО ПЛОТНОСТЬ, ВЯЗКОСТЬ И СРОК СТАБИЛЬНОСТИ.

\begin{tabular}{|c|c|c|c|c|c|c|c|}
\hline \multirow{2}{*}{$\begin{array}{c}\text { № } \\
\Pi / \Pi\end{array}$} & \multicolumn{4}{|c|}{ Состав раствора, моль } & \multicolumn{3}{|c|}{ Свойства раствора } \\
\hline & ТЭОС & $\mathrm{H}_{2} \mathrm{O}$ & $\mathrm{HC} 1$ & спирт & $\begin{array}{c}\text { Плотность, } \\
\Gamma / \mathrm{cm}^{3} \\
\end{array}$ & Электропроводность, мСм. & $\begin{array}{c}\text { Вязкость, } \\
\text { сПа }\end{array}$ \\
\hline 1 & 1 & 1 & 0,05 & 30 & 0,8248 & 9,6 & 1,7 \\
\hline 3 & 1 & 4 & 0,05 & 30 & 0,8295 & 10,0 & 1,8 \\
\hline 5 & 1 & 10 & 0,05 & 30 & 0,8365 & 10,4 & 2,1 \\
\hline 7 & 1 & 20 & 0,05 & 30 & 0,8578 & 16,5 & 2,3 \\
\hline 9 & 1 & 30 & 0,05 & 30 & 0,8631 & 18,5 & 2,4 \\
\hline 11 & 1 & 40 & 0,05 & 30 & 0,8684 & 20,0 & 2,6 \\
\hline
\end{tabular}

Как следует из данных приведенных в таблице 2, с увеличением количества $\mathrm{H}_{2} \mathrm{O}$ возрастает вязкость раствора. При дсодержании воды в растворе от 1 до 40 моль, т,е при соотношении $\mathrm{H}_{2} \mathrm{O}$ /ТЭОС до 40 увеличивает вязкость в 1,53 раза. Из результатов проведенных экспериментов следует, что при соотношение $\mathrm{H}_{2} \mathrm{O} / \mathrm{T} Э \mathrm{OC}=20$ данный раствор можно использовать для изготовления газочувствительной пленок в течение 445 часов.

Влияние содержания ТЭОС в гидролизате на устойчивость пленкообразующего золя изучали в интервале его содержания в растворе от 1 до 4 моль. Динамика изменения вязкости от продолжительности опыта при различных содержаниях ТЭОС в растворе представлена на рис. 5. Как видно из данных рис. 5, наиболее высокой стабильностью характеризуются раствор приготовленной при соотношение компонентов (в моль): 1-ТЭОС : 20- ${ }_{2} \mathrm{O}: 30-с п и р т: 0,05-\mathrm{HCl}$.

Полученные результаты показали снижение периода гелеобразования с ростом концентрации ТЭОС в растворе. Результаты экспериментов подтверждают целесообразность проведения синтеза газочувствительных пленок при низких концентрациях ТЭОС в реакционном растворе. Использование последнего позволяет получить однородный гель с большим сроком стабильности и без признаков седиментации.

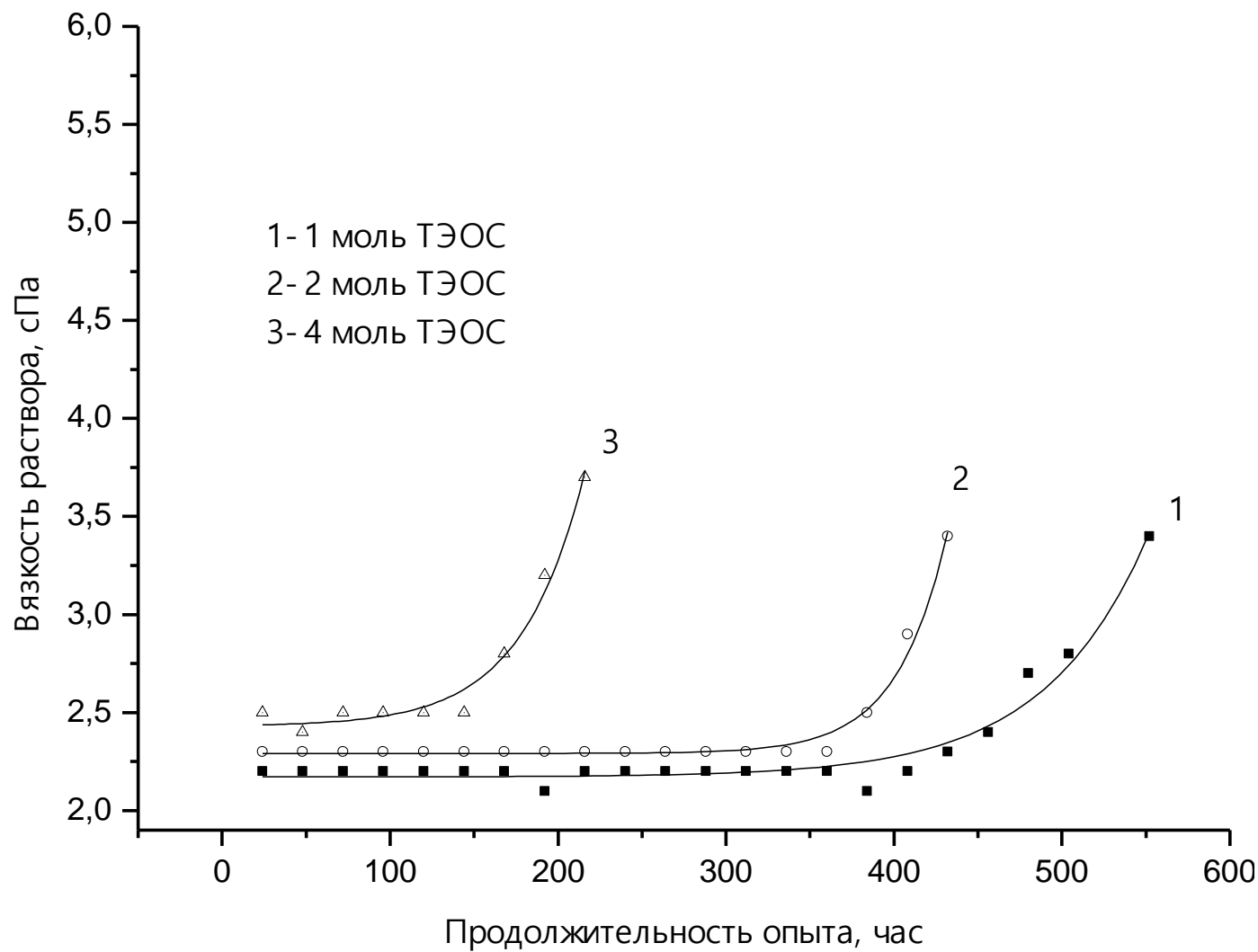

рис. 5. График зависимости вязкости от продолжительности опыта при различных содержаниях ТЭОС в растворе: ТЭОС:Н2О:этанол:НС1.

(Содержание в растворе: Н2О-20 моль; этанол-30 моль; НС1-0,05 моль).

Влияние $\mathrm{pH}$ среде на устойчивость, плотность, электропроводность, вязкость и степень гидролиза изучали в диапазоне ТЭОС:HC1 равной от 1:0,01моль до 1:0,30 моль. Результаты опытов приведены в таблице 4. 
Таблица 4.

ЗАВИСИМОСТЬ СВОЙСТВ РАСТВОРА ОТ СОДЕРЖАНИЯ НС1 В СМЕСИ: ТЭОС:Н2О: СПИРТ:НС1 (СОДЕРЖАНИЕ В ИСХОДНОМ ГИДРОЛИЗАТЕ ТЭОС-1МОЛЬ,

Н2О-20 МОЛЬ, СПИРТ-30 МОЛЬ).

\begin{tabular}{|c|c|c|c|c|c|c|c|c|c|c|}
\hline \multirow[b]{2}{*}{$\begin{array}{c}\text { № } \\
\Pi / \Pi\end{array}$} & \multicolumn{5}{|c|}{ Состав раствора } & \multicolumn{5}{|c|}{ Свойства раствора } \\
\hline & 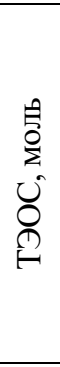 & 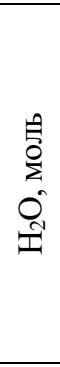 & 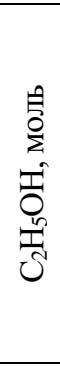 & 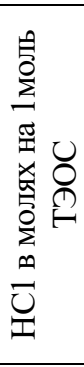 & 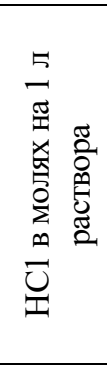 & 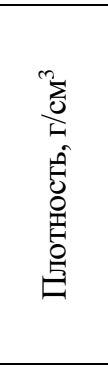 & 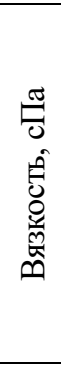 & 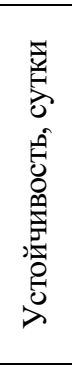 & 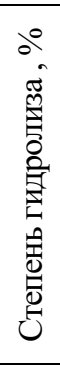 & 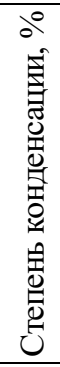 \\
\hline 1 & 1 & 20 & 30 & 0,01 & 0,0029 & 0,8544 & 2,4 & 17,5 & 96 & 100 \\
\hline 2 & 1 & 20 & 30 & 0,05 & 0,0146 & 0,8571 & 2,4 & 20,5 & 96 & 100 \\
\hline 3 & 1 & 20 & 30 & 0,10 & 0,0293 & 0,8601 & 2,5 & 8,0 & 98 & 97 \\
\hline 4 & 1 & 20 & 30 & 0,20 & 0,0586 & 0,8642 & 2,5 & 7,0 & 97 & 82 \\
\hline 5 & 1 & 20 & 30 & 0,30 & 0,0878 & 0,8671 & 2,6 & 6,0 & 98 & 72 \\
\hline
\end{tabular}

В изученном диапазоне концентраций с повышением концентрации кислоты в растворе увеличивается его плотность от 0,8544 до 0,8671

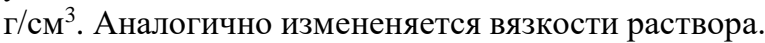
В интервале соотношения ТЭОС: НС1 от 1:0,01 до 1:0,30 моль вязкость раствора увеличивается на от 2,4 до 2,6 сПа).

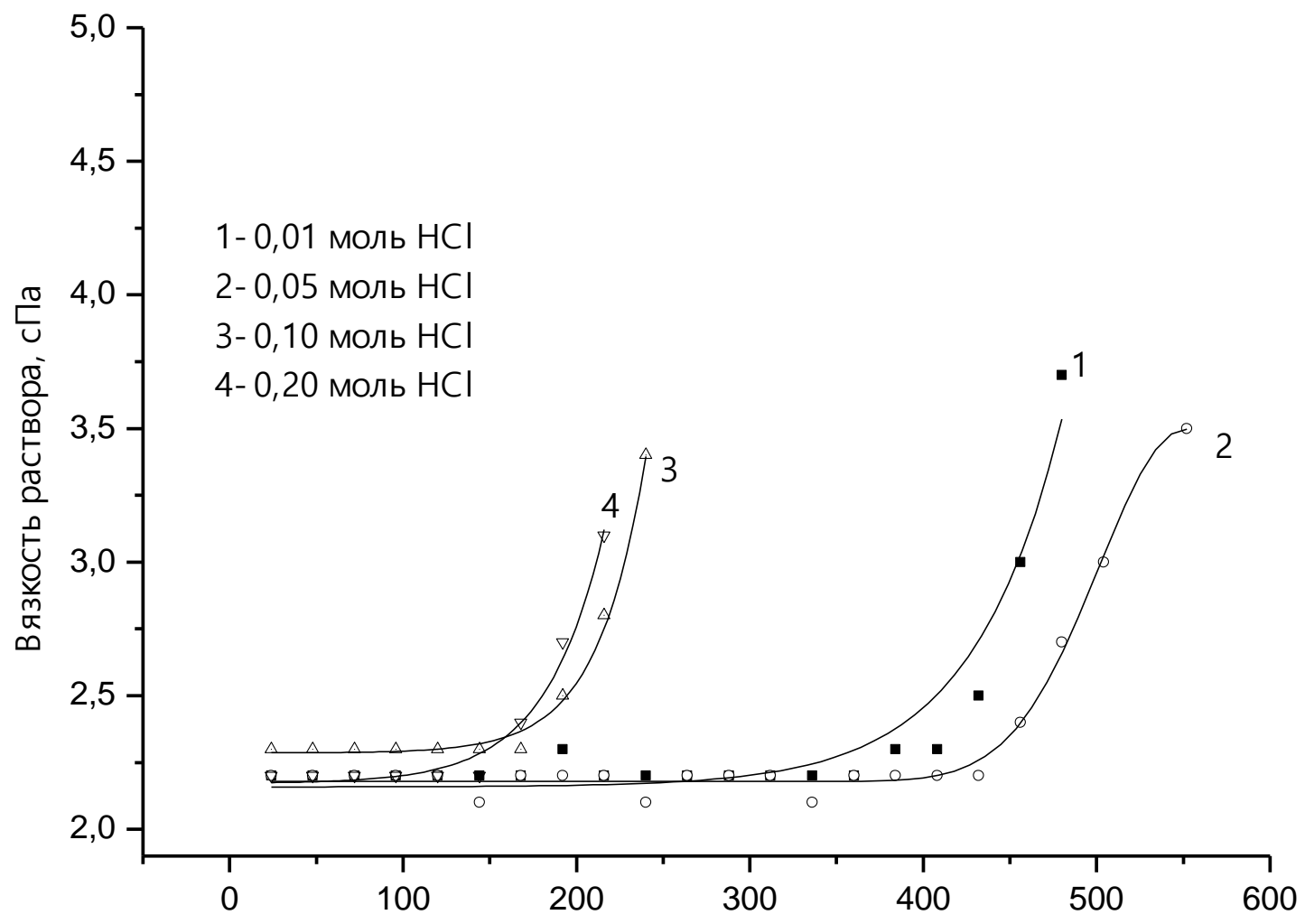

Продолжительность опыта, час

рис. 6. График зависимости вязкости от продолжительности опыта при различных содержаниях НС1 в растворе: ТЭОС:Н2О:этанол:НС1.

(Содержание в растворе: ТЭОС-1 Н2О-20 моль; этанол-30 моль).

Наиболее оптимальным для получения газочувствительных пленок является соотношение 
ТЭОС:НC1=0,05 (см. график 2, рисунка 6.) при котором обеспечивается 450 часовая устойчивость раствора.

Таким образом, наиболее важным параметром золь-гель синтеза газочувствительных пленок, является рН среды. При значениях ТЭОС/HC1 $\geq 20,0$ гидролиз разбавленных растворов ТЭОС в спиртовой среде при комнатной температуре (20 ${ }^{\circ} \mathrm{C)}$ протекает долго. Следовательно, устойчивые золи легче всего получать при низких концентрациях НC1 и в разбавленных растворах, так как в таких системах малы скорость образования частиц и их рост (из-за небольших степеней пресыщения и из-за медленной диффузии фазообразующего вещества к поверхности зародыша).

\section{Заключение.}

Таким образом, в результате проведенных исследований влияния состава и соотношения компонентов пленкообразующих растворов на кинетику процесса гелеобразования исходного золя подобраны оптимальные параметры, обеспечивающие высокую устойчивость исходного раствора. Установлено, что наибольшей устойчивостью обладают растворы, полученные при соотношении исходных компонентов ТЭОС: $\mathrm{H}_{2} \mathrm{O}:$ спирт:НC1=1:20:30:0,05. Раствор, полученный при оптимальных условиях, устойчив от 18 до 18,5 суток.

\section{Список использованной литературы:}

1. Мясников И.А., Сухарев В.Я., Куприянов Л.Ю., Завьялов С.А. Полупроводниковые сенсоры в физико-химических исследованиях // М.: Наука, 1991. $327 \mathrm{c}$.

2 Бубнов Ю.3., Шилова О.А Наноразмерные стекловидные пленки многофункционального назначения в технологии изготовления полупроводниковых газовых сенсоров // Технологии приборостроения. 2003. №3 (7). С. 6071.

3.Абдурахманов И.Э. Создание селективных газовых сенсоров аммиака на основе наноматериалов. LAP LAMBERT Academic Publishing. Beau Bassin (Германия) 2018. P.121.

\title{
СИНТЕЗ И МОЛЕКУЛЬЯРНАЯ И КРИСТАЛЛИЧЕСКАЯ СТРУКТУРА ПАРА - ОКСИБЕНЗОАТА ҮВ(III).
}

\author{
Касумова Самира Али кызы. \\ Докторант Гянджинского филиала \\ Национальная АН Азербайдана
}

\section{SYNTHESIS OF MOLECULAR AND CRYSTALLINE STRUCTURE OF PARA- HYDROXYBENZOATA YB (III).}

\author{
Kasımova Samira Ali kızı \\ Doctoral student of the Ganja branch of the \\ National Academy of Sciences of the Republic of Azerbaijan
}

\section{АННОТАЦИЯ}

Синтезировано новые комплекс пара-оксибензойнои кислоты с Yb (III), - получена монокристаллы для рентгенструктурнова анализа и расшифрована молекулярная и кристаллического структура нового комплекса. Установлено что, метал координируется килородами карбоксилной группы монодентадно, бидентатно и бидентатно-мостикова типа.

\section{ABSTRACT}

New para-oxybenzoic acid complex with $\mathrm{Yb}$ (III) was synthesized, single crystals were obtained for X-ray diffraction analysis and the molecular and crystalline structure of the new complex was deciphered. It has been established that the metal is coordinated by the carboxyl group kilorods monodentadno, bidentate and bidentatebridge type.

Ключевые слова: пара-оксибензойнои кислота, рентгенструктурный анализ, комплекс $\mathrm{Yb}$ (III), монодентадный, бидентатный, бидентатно-мостиковые связьи. bridge.

Key words: para-oxybenzoic acid, X-ray analiz, complex Yb (III), monodentadno, bidentate and bidentate-

Пара - оксибензойная кислота -4 - НО$\mathrm{C}_{6} \mathrm{H}_{4} \mathrm{COOH}$ встречается в почвах [1], в морской воде[2] и различных органах растений: листьях и ягодах виноградника [3], сахарной свекле [4], томатах [5]. Биологическая активность пара оксибензойной кислоты изучено достаточно: синтез стеринов в ткани головного мозга, стимулирует реакции секреции кислоты желудка на тетрачастрин и повышает базальную секрецию [6].

Строение пара - оксибензойной кислоты установлено при расшифровке структуры [7]. Монокристаллы п - $\mathrm{HO}-\mathrm{C}_{6} \mathrm{H}_{4} \mathrm{COOH}$ моноклинные: 